\title{
REFLEXOS DO PRINCÍPIO CONSTITUCIONAL DO DEVIDO PROCESSO LEGAL NO DIREITO INFANTO-JUVENIL
}

\author{
Mario Augusto de Souza ${ }^{1}$
}

\begin{abstract}
Resumo: O presente artigo objetiva analisar o direito fundamental do devido processo legal à luz do Direito infanto-juvenil e as garantias processuais dele decorrentes. Utilizar-se-á a pesquisa bibliográfica para demonstrar que a observância desse direito fundamental é indispensável para que, no caso de responsabilização do adolescente infrator, suas necessidades pedagógicas sejam realmente atendidas, em obediência aos princípios da brevidade, da excepcionalidade e do melhor interesse desses seres em processo de formação, respeitando-se, assim, os direitos fundamentais que lhe são próprios.
\end{abstract}

Palavras-chave: devido processo legal; garantias processuais; responsabilidade; adolescente infrator.

\section{REFLECTIONS ON THE CONSTITUTIONAL PRINCIPLE OF THE DUE PROCESS OF LAW ON THE CHILDREN AND TEENAGERS RIGHTS}

\begin{abstract}
This article intends to analyze the basic right of the due process of law according to the constitutional rights for children and teenagers also considering the guarantees coming from them. The bibliographical research is used to demonstrate that the observance of this basic right is imperative so that, in a case of accountability of the young offender, his pedagogical needs may be really granted, in obedience to the principles of brevity, of exceptionality and taking into account the best interests of those beings who are in a social formation process, respecting therefore the basic rights that are applicable for them.
\end{abstract}

Keywords: due process of law; lawsuit guarantees; responsibility; young offender.

\footnotetext{
${ }^{1}$ Mestrando em Direito pelo Centro UNISAL-Lorena. Pós-graduado em Direito Civil e Processo Civil pelo Centro UNISAL-Lorena e em Direito Penal e Processo Penal pela AVM Faculdades Integradas. Licenciando em Pedagogia pela UNITAU. Professor do Centro Estadual de Educação Tecnológica Paula Souza - CEETEPS. Advogado. Contato: mario.mas@ig.com.br
} 


\section{Introdução}

Orientado pelas regras internacionais que tutelam os direitos da criança e do adolescente, em especial pela Convenção sobre os Direitos da Criança, pelas Regras de Beijing, pelas Diretrizes de Riad, bem como pela Constituição Federal de 1988, o Esta tuto da Criança e do Adolescente vige há mais de duas décadas, estabelecendo, em seu artigo 111, várias garantias processuais decorrentes do princípio do devido processo legal.

Em razão da cultura punitiva da sociedade, da distorção na interpretação do Estatuto da Criança e do Adolescente e dos problemas da própria legislação infanto-juvenil, essas garantias processuais muitas vezes são inobservadas ou aplicadas em desconformidade com as diretrizes do Direito da Criança e do Adolescente, implicando, com isso, responsabilização penal do adolescente infrator com imposição de medi das socioeducativas sem qualquer correlação com sua finalidade precípua, qual seja, a necessidade pedagógica desse ser em condição peculiar de desenvolvimento.

Desse modo, pretende-se, por meio desse artigo, analisar as garantias processuais do adolescente infrator estampadas no artigo 111, do Estatuto da Criança e do Adolescente, enquanto reflexos do princípio do devido processo legal, consoante o enfoque diferenciado que reclamam, por destinarem-se aos adolescentes em conflito com a lei.

Para tanto, inicialmente, abordar-se-á algumas considerações sobre a responsabilidade do adolescente infrator e, após, analisar-se-á o princípio do devido processo legal à luz das diretrizes do Estatuto da Criança e do Adolescente, focando-se, ao final, nas garantias processuais explícitas na norma estatutária que, pautadas na proteção integral, afastaram o reflexos da situação irregular no procedimento de apuração do ato infracional, em consonância com os instrumentos internacionais que referenciam os direitos infanto-juvenis.

\section{Considerações sobre a responsabilidade do adolescente infrator}

Regulamentando a política de atendimento à infância e à juventude no país, o Estatuto da Criança e do Adolescente seguiu a injunção dos instrumentos internacionais de proteção dos direitos da criança e do adolescente, em especial a Convenção sobre os Direitos da Criança, as Regras de Beijing e as Diretrizes de Riad, estabelecendo um sistema de garantia de direitos a todas as crianças e adolescentes, pautado num constante cuidado especial com esses seres, independentemente de classe social ou situação em que se encontram. Com isso, evidenciou 
novos conceitos de participação, responsabilidade e protagonismo juvenil, passando a considerar a criança e o adolescente sujeitos de direitos.

O Estatuto da Criança e do Adolescente é norteado pelo princípio de que todas as crianças e todos os adolescentes, sem distinção, desfrutam dos mesmos direitos dos adultos e pressupõem obrigações compatíveis com a peculiar condição de pessoas em desenvolvimento.

Referida norma estatutária, portanto, transformou o paradigma da situação irregular, antes vivenciado com o Código de Menores, em proteção integral, em consonância com as normas internacionais de proteção dos direitos das crianças e dos adolescentes, sendo certo que a Constituição Federal de 1988, em seu artigo 2 27, atribuiu à família, à sociedade e ao Estado o dever de tutelar os direitos das crianças e dos adolescentes, cabendo-lhes protegê-los contra qualquer tipo de atentado à sua dignidade e aos seus direitos fundamentais, dispensando sempre a eles um cuidado especial.

Logo em seu preâmbulo, a Convenção sobre os Direito s da Criança ressalta que na Declaração Universal dos Direitos Humanos as Nações Unidas proclamaram que a infância tem direito a cuidados e assistência especiais e que, de acordo com os princípios anunciados na Carta das Nações Unidas, a liberdade, a justiça e a paz no mundo se fundamentam no reconhecimento da dignidade inerente e dos direitos iguais e inalienáveis de todos os membros da família humana.

Acerca da Convenção Internacional da Organização das Nações Unidas sobre os Direitos da Criança, Norberto Bobbio (2004, p. 34) aduz que:

[...] a criança, por causa de sua imaturidade física e intelectual, necessita de uma proteção particular e de cuidados especiais, deixando-se assim claro que os direitos da criança são considerados como um ius singulare com relação a um ius commune; o destaque se dá a essa especificidade, através do genérico, no qual se realiza o respeito à máxima a sum couidque tribuere. Logo, cuida dos direitos da criança como uma especificação da solução dada aos problemas dos direitos do homem.

Analisando o cuidado especial estabelecido pela Convenção sobre os Direitos da Criança, Tânia da Silva Pereira (2008, p. 73) explica que “O cuidado é parte integral da vida humana: nenhum tipo de vida subsiste sem cuidado”, logo, o sistema de proteção à criança e ao adolescente pauta-se na proteção integral, no melhor interesse e no cuidado especial que se deve ter em relação a esses seres em processo de formação.

O Estatuto da Criança e do Adolescente, ao estabelecer o sistema de proteção integral às crianças e aos adolescentes, assegurou juridicamente direitos e garantias fundamentais a esses seres em desenvolvimento, elevando-os à categoria jurídica de sujeitos de direito, conforme asseverado alhures, sendo certo que tais direitos devem "ser vistos em suas peculiaridades e 
particularidades”, em razão d a condição peculiar de formação que ostentam, e interpretados de modo a atender seu melhor interesse (PIOVESAN, 2010, p. 151).

Esses direitos fundamentais, que correspondem ao mínimo de direitos necessários para assegurar uma vida com dignidade e liberdade, visam assegurar o desenvolvimento, o crescimento, o cumprimento de suas potencialidades, o tornar-se cidadãos adultos livres e dignos, ou seja, são direitos exigíveis pela dignidade humana, macro princípio que orienta todo o ordenamento jurídico e os instrumentos internacionais que referenciam os direitos da criança e do adolescente (VERCELONE , 2005, p. 34).

Consoante leciona Maria Aparecida Alkmin (2016, p. 60):

O sistema de proteção aos direitos infanto-juvenis traçado pela Convenção sobre os Direitos da Criança tem caráter universalista, obrigatório e vinculante, sendo certo que o fim precípuo de todo o sistema de proteção é a concretização da dignidade humana da criança e do adolescente e, nesse sentido, o artigo $39^{\circ}$ da CDC anuncia que todo sistema internacional de proteção aos direitos da criança converge para a preservação da dignidade da criança.

Os direitos fundamentais infanto-juvenis, segundo aduz Tânia da Silva Pereira (2008, p. 151), “são norteados pela trilogia da proteção integral”, que esta disciplinada no Estatuto da Criança e do Adolescente (artigo 15), na medida em que determina que criança e adolescente são titulares de liberdade, respeito e dignidade como pessoas em processo de desenvolvimento.

Desse modo, às crianças e aos adolescentes são assegurados vários direitos fundamentais que tutelam seu desenvolvimento integral, tais como a vida, saúde, liberdade, respeito, dignidade, convivência familiar e comunitária, educação, cultura, esporte, lazer, profissionalização e proteção ao trabalho. Ou seja, o desenvolvimento integral contempla o respeito à condição peculiar de desenvolvimento biológico, social, cultural, educacional e moral da criança e do adolescente, independentemente de sexo, raça e condição social, sendo certo que, qualquer medida de intervenção que reflita no seu desenvolvimento enquanto ser humano e, sobretudo, em sua liberdade, deve zelar pelo respeito aos direitos infanto-juvenis, em apreço ao melhor interesse da criança e do adolescente.

Seguindo a injunção dos instrumentos internacionais de proteção à infância e à adolescência, a Constituição Federal e o Estatuto da Criança e do Adolescente previram a imputabilidade penal aos dezoito anos completos, todavia, não excluíram a possibilidade de se aplicar às crianças e aos adolescentes, respectivamente, medidas de proteção e medidas socioeducativas.

Nesse sentido, explica João Batista Costa Saraiva ( 2016, p. 133): 
A inimputabilidade penal do adolescente, cláusula pétrea instituída no art. 228 da Constituição Federal, aspecto já destacado nesse estudo, significa fundamentalmente a insubmissão do adolescente por seus atos às penalizações previstas na legislação penal, o que não o isenta de responsabilização e sancionamento.

As medidas protetivas destinam-se às crianças (até doze anos incompletos) que apresentem uma situação de risco ou violação de direito, podendo ser aplicada independentemente de intervenção judicial, com envolvimento da família, submetendo-se os pais ou responsáveis às penas e restrições impostas pela justiça.

Já os adolescentes, que possuem entre doze e dezoito anos incompletos, estão sujeitos ao sistema de justiça especial e à aplicação de medidas socioeducativas quando da prática de ato infracional, isto é, conduta semelhante à definida em lei como crime ou contravenção penal (artigo 103, do ECA).

Tais medidas, previstas no art. 112, do Estatuto da Criança e do Adolescente, classificam-se em advertência; obrigação de reparar o dano; prestação de serviços à comunidade; liberdade assistida; inserção em regime de semiliberdade; internação em estabelecimento educacional; e qualquer uma das medidas previstas no art. 101, I a VI, do mesmo Diploma Legal.

Segundo Paulo Afonso Garrido de Paula (2002, p. 34):

O traço de instrumentalidade da tutela diferenciada consiste na concepção de que a
medida socioeducativa serve como instrumento de defesa social, ao mesmo tempo em
que se consubstancia como meio de intervenção no desenvolvimento do jovem. Do
cotejo dos elementos dessa instrumentalidade que se extrai a adequação da medida
socioeducativa a ser definida no caso concreto, não guardando relação direta com o
ato infracional praticado. Por isso o legislador não vinculou diretamente certo at o
infracional com determinada medida socioeducativa, ficando sempre ao encargo da
autoridade judiciária compor os elementos da instrumentalidade, à luz das
particularidades do caso concreto.

Com isso, a norma estatutária instituiu no país um sistema de responsabilidade do adolescente em conflito com a lei que, por sua natureza garantista, inspirado nos princípios que limitam o poder sancionador estatal, pode ser definido como de Direito Penal Juvenil, já 
que o foco do exercício se dá em relação à condição peculiar de pessoa em desenvolvimento de que desfruta o adolescente.

Consoante João Batista Costa Saraiva (2016, p. 97/9 8):

Não se pode ignorar que o Estatuto da Criança e do Adolescente instituiu no país um sistema que pode ser definido como Direito Penal Juvenil. Estabelece um mecanismo de sancionamento, de caráter pedagógico em sua concepção e conteúdo, mas evidentemente retributivo em sua forma, articulado sob o fundamento do garantismo penal e de todos os princípios norteadores do sistema penal enquanto instrumento de cidadania, fundado nos princípios do Direito Penal Mínimo.

Independentemente da espécie, a medida socioeducativa possui finalidade retributiva, preventiva e, sobretudo, reeducativa, residindo, nesse último propósito, o mais relevante caráter diferenciador dessas medidas em relação à pena imposta aos adultos, o que legitima um tratamento diferenciado, pautado no princípio do melhor interesse, ao adolescente infrator no que tange à sua responsabilização penal. Ou seja, tais medidas, observando-se a condição de pessoa em desenvolvimento do adolescente, visam propiciar sua reeducação e ressocialização na sociedade.

Aliás, consoante dispõe a Convenção Sobre os Direitos da Criança, em seu artigo $3^{\circ}$, “Todas as ações relativas às crianças, levadas a efeito por instituições públicas ou privadas de bem estar social, tribunais, autoridades administrativas ou órgãos legislativos, devem considerar, primordialmente, o melhor interesse da criança” e, nos termos do item 4, c, das Diretrizes de Riad, as políticas e medidas progressistas de prevenção da delinquência que evitem criminalizar e penalizar a criança por uma conduta que não causa grandes prejuízos ao seu desenvolvimento deverão conter "uma intervenção oficial cuja a principal finalidade seja a de velar pelo interesse geral do jovem e que se inspire na justiça e na equidade”.

Há que se considerar, ainda, que a fixação das medidas socioeducativas como resposta ao ato infracional perpetrado, que deverão levar em conta a capacidade de cumprimento pelo adolescente, as circunstâncias e a gravidade da infração (artigo 112, § $1^{\circ}$, do ECA), também se sujeitam ao princípio da adoção de medidas sem que haja necessidade de processo judicial, por meio do exercício da justiça restaurativa, sendo certo que, assim como no ocorre com os princípios norteadores da responsabilização penal de um adulto, o processo judicial de apuração de ato infracional somente existirá em ultima ratio, quando não surtirem efeito os procedimentos de justiça restaurativa aplicados. 
Sobre esse modelo de justiça exercido no campo do Direito Penal Juvenil, inclusive no que tange à execução das medidas socioeducativas , explica Luciano Rossato (2016, p. 346) que:

[...] insere-se como medida extremamente vantajosa a implantação da Justiça Restaurativa, cujo objetivo, em apartada síntese, é promover a aproximação entre sociedade e adolescente infrator, em contraposição ao modelo em que a sociedade tem a função acusadora e o adolescente o direito de oposição a essa pretensão. Ao promover essa aproximação, busca-se a pacificação social, mediante a qual o adolescente passará a entender a sua importância no contexto social.

Portanto, havendo necessidade de se responsabilizar o adolescente infrator pela prática do ato infracional por meio de intervenção judicial, a aplicação de qualquer medida socioeducativa deve preceder de um devido processo legal que, obrigatoriamente contemple, além do respeito aos direitos fundamentais infanto-juvenis, a estrita observância das garantias processuais do adolescente, afinal, a medida de intervenção, apesar de condicionada aos princípios da brevidade, da excepcionalidade e do melhor interesse, pode implicar reflexos na liberdade do adolescente que, enquanto direito fundamental, se sofrer limitações desarrazoadas, refletirá distorção do verdadeiro propósito da responsabilização penal desse ser em formação.

\section{O devido processo legal à luz das diretrizes do Dir eito da Criança e do}

\section{Adolescente}

O Estatuto da Criança e do Adolescente, conforme asseverado anteriormente, contrapondo-se completamente ao Código de Menores, reafirmou a condição de sujeito de direito às crianças e aos adolescentes, seguindo as normativas internacionais de proteção aos direitos desses seres em desenvolvimento. Com isso, assegurou as garantias processuais aplicáveis ao direito infanto-juvenil com um enfoque diferenciado em razão da condição especial de pessoas em processo de formação.

Nesse sentido, explica Valter Kemji Ishida (2011, p. 238):

Dentro da adoção da doutrina da proteção integral e contrapondo-se ao anterior direito da situação irregular, o "procedimento para o adolescente em conflito com a lei” passou a possuir regras mais $\mathrm{cl}$ aras que garantissem o direito à ampla defesa e ao contraditório do adolescente. O capítulo III denominado “das garantias processuais” nada mais as sinala sobre essa mudança de atitude da lei menorista, que passou a p regar o garantismo do procedimento menorista como uma das bandeiras dessa nova visão do direito infracional. 
Considerado o princípio basilar das garantias processuais, o devido processo legal é o que garante a todos o direito a um processo com todas as etapas previstas em lei, dotado de todas as garantias existentes, as quais asseguram diversos direitos.

Esse princípio desenvolveu-se a partir do sistema jurídico inglês e tem origem na Magna Carta de João Sem Terra, de 1215. Além de estar expressamente anotado na Constituição Federal enquanto direito fundamental, o devido processo legal também está previsto em outros instrumentos normativos, tais como a Declaração Universal dos Direitos Humanos e a Convenção Americana Sobre os Direitos Humanos.

O princípio do devido processo legal contempla não somente a legalidade, mas também a legitimidade, na medida em que sua observância assegura um processo devidamente estruturado, no qual a jurisdição, entendida como poder, função e atividade estatal, seja legitimamente exercitada. Tal princípio está previsto no artigo 5 , LIV, da Constituição Federal, que determina que "ninguém se rá privado da liberdade ou de seus bens sem o devido processo legal”, bem como no Estatuto da Criança e do Adolescente, em seu artigo 110, que determina que "nenhum adolescente s erá privado de sua liberdade sem o devido processo legal”.

Consoante lição de Guilherme de Souza Nucci (2016, p. 421):

O devido processo legal significa, sob o ponto de vista material, a fiel observância dos princípios penais (legalidade, anterioridade, taxatividade, proporcionalidade, responsabilidade pessoal etc.) e, sob o prisma processual, o respeito aos princípios processuais (ampla defesa, contraditório, publicidade, juiz natural etc.).

Esse princípio pode ser interpretado sob a ótica substancial e processual. Na vertente substancial, o devido processo legal determina que as leis devem satisfazer ao interesse público, aos anseios do grupo social a que se destinam, evitando ao mesmo tempo o abuso de poder por parte do Estado, garantindo às pessoas a elaboração legislativa comprometida com os reais interesses sociais. Já sob a ótica processual, o devido processo legal representa a exigência, tanto nos processos judiciais quanto administrativos, da observância de diversos direitos, tais como o contraditório, a ampla defesa , o duplo grau de jurisdição, dentre outros.

Segundo Ricardo Cunha Chimenti (2006, p. 68):

Bastaria tal princípio para que daí decorressem todas as consequências processuais que garantiriam aos litigantes o direito a um processo e a uma sentença justa. Esse princípio é, portanto, o gênero do qual os demais princípios constitucionais do processo são espécies: o princípio da publicidade, da motivação, do juiz natural, do contraditório, da ampla defesa, da impossibilidade de utilização em juízo da prova obtida por meio ilícito etc. 
De acordo com Alexandre de Moraes (2007, p. 95):

O devido processo legal configura dupla proteção ao indivíduo, atuando tanto no âmbito material de proteção ao direito de liberdade, quanto no âmbito formal, ao assegurar-lhe paridade total de condições com o Estado-persecutor e plenitude de defesa.

Todos os direitos processuais existentes derivam do princípio do devido processo legal e, em se tratando de criança e adolescente, q ue reclamam cuidado especial, esse princípio deve ser observado de forma especial pelo operador do direito, justamente em razão da condição peculiar de desenvolvimento daquele que sobre o processo de apuração do ato infracional ou a própria execução de medida socioeducativa.

Decorrentes do devido processo legal, as garantias processuais do adolescente infrator compreendem, além de outras, conforme Pinto Ferreira (1989, p. 49):

\begin{abstract}
a) o direito à citação, pois ninguém pode ser acusa do sem ter conhecimento da acusação; b) o direito de arrolamento de testemunhas, que deverão ser intimadas para comparecer perante a Justiça; c) o direito ao procedimento contraditório; d) o direito de não ser processado por leis ex post fact; e) o direito de igualdade com a acusação; f) o direito d e ser julgado mediante provas e evidência legal legitimamente obtidas; g)o direito ao juiz natural; h) o privilégio contra a auto-incriminação; i) a indeclinabilidade da prestação jurisdicional, quando solicitada; j) o direito aos recursos; l) o direito à decisão com eficácia de coisa julgada.
\end{abstract}

Ainda, o Estatuto da Criança e do Adolescente, em s eu artigo 111, estabelece outras garantias processuais decorrentes do devido processo legal, as quais também se encontram disciplinadas em instrumentos internacionais de proteção à criança e ao adolescente, a exemplo da Convenção sobre os Direitos da Criança que, em seu artigo 40, destaca várias garantias aqueles seres a quem se atribua a prática de ato infracional, tais como a presunção de inocência, o direito à informação da acusação que lhe é atribuída; celeridade processual; assistência jurídica integral; confrontar-se com vítimas e testemunhas; direito ao duplo grau de jurisdição; assistência de intérprete; respeito à sua vida privada; adoção de medidas sem que haja necessidade de processo judicial.

Essas garantias processuais asseguradas ao adolescente infrator não são exaustivas, sendo perfeitamente possível, mormente em apreço ao princípio do melhor interesse, a aplicação de outras garantias durante o procedimento de apuração do ato infracional ou da execução da medida socioeducativa, afinal, aos adolescentes aplicam-se todos os direitos e garantias fundamentais aplicáveis aos adultos, além daqueles que lhes são próprios em razão da sua condição de sujeito em desenvolvimento, a fim de proteger seus direitos fundamentais, em especial a liberdade. 
Aliás, consoante dispõe as Regras de Beijing (item 17.1), o Sistema de Justiça Juvenil para os Estados no âmbito das Nações Unidas é norteado pelos princípios seguintes, que se encontram também inseridos no âmbito do devido processo legal, a saber:

a) A resposta à infração será sempre proporcional não só às circunstâncias e à gravidade da infração, mas também às circunstâncias e às necessidades do jovem, assim como às necessidades da sociedade; b) As restrições da liberdade pessoal do jovem serão impostas somente a pós estudo cuidadoso e se reduzirão ao mínimo possível; c) Não será imposta a privação de liberdade pessoal a não ser que o jovem tenha praticado ato grave, envolvendo violência contra outra pessoa ou por reincidência ou cometimento de outras infrações sérias, e a menos que não haja outra medi da apropriada; d) O interesse e bem-estar do jovem será o fator preponderante no exame dos casos.

O devido processo legal, que se materializa no procedimento de apuração do ato infracional e de execução de medida socioeducativa, deve observar necessariamente o princípio da celeridade processual e razoável duração do processo, sem prejuízo das garantias processuais dele decorrentes, afinal, à luz do princípio constitucional da prioridade absoluta (art. 227, da CF), as ações destinadas ao adolescente a quem se atribui a prática de ato infracional devem ter primazia (art. $4^{\circ}$, do ECA), ou seja, devem ser executadas de modo a garantir respostas rápidas às necessidades pedagógicas do adolescente e, consequentemente, à sua recuperação e reintegração social.

De igual modo, em especial ao adolescente sujeito ao procedimento infracional, a Convenção das Nações Unidas sobre os Direitos da Criança, em seu artigo 40, salienta a necessidade de urgência, partindo do pressuposto que o processo educativo do jovem supõe presteza e imediatismo.

Destarte, concretizar adequadamente a garantia processual do devido processo legal, que integra o conjunto dos direitos fundamentais infanto-juvenis, representa assegurar o exercício da própria cidadania ao adolescente a que m se atribui a prática do ato infracional, ou seja, assegurar o devido processo legal ao adolescente submetido ao procedimento de apuração de ato infracional, inclusive em fase de execução de medida socioeducativa, não é apenas assegurar uma simplória defesa, mas sim zela pela correta intervenção estatal que atenda às suas necessidades pedagógicas, com respeito aos seus direitos fundamentais.

\section{Garantias processuais estatutárias aplicáveis ao procedimento de apuração do}

\section{ato infracional}


Consoante salientado anteriormente, o adolescente a quem se atribui a prática de ato infracional tem os mesmos direitos de uma pessoa adulta sujeita aos procedimentos que podem implicar o exercício do poder de punir do Estado, além daqueles que lhe são próprios em razão da peculiar condição de pessoa em desenvolvimento.

Nessa esteira, leciona João Batista Costa Saraiva ( 2016, p. 111):

Ao adolescente que se atribui a autoria de ato infracional reconhecem-se todas as garantias mais outras, próprias da sua con dição peculiar de pessoa em desenvolvimento, em um plus de garantias, que se tem denominado discriminação positiva.

Portanto, há integral aplicação das disposições de cunho garantista da seara do processo penal ao adolescente em conflito com a lei.

As garantias processuais decorrentes do princípio constitucional do devido processo legal, consubstanciadas no artigo 111 do Estatuto da Criança e do Adolescente, são:

\section{a. Direito ao pleno e formal conhecimento da atribuição do ato infracional,} mediante citação ou ato equivalente

Dentre as garantias processuais que integram o princípio do devido processo legal, explicitamente previstas no Estatuto da Criança e d o Adolescente e também na Constituição Federal (art. 227, § $3^{\circ}$, inc. IV), encontra-se o direito ao pleno e formal conhecimento da atribuição do ato infracional que lhe é feita, o qual é fundamental ao adolescente, mormente para o exercício da ampla defesa.

Daí a necessidade de, ao descrever a representação, nos casos em que couber, o Ministério Público observar a correta descrição dos fatos, com todas as suas circunstâncias, bem como os demais requisitos da peça inicial acusa tória exigíveis no processo penal comum, evitando-se, com isso, imputação não específica em detrimento do adolescente e prejuízo ao exercício de sua defesa, pessoal ou técnica.

Não se pode olvidar, ainda, que esse direito não deve ser observado apenas na fase de eventual procedimento de apuração do ato infracional, afinal, na hipótese de ser apreendido em flagrante delito, o adolescente em conflito com a lei tem o direito a ser cientificado sobre o motivo da sua apreensão, bem como à comunicação d os seus responsáveis (art. 5º, LXIII, da CF e art. 37, item $c$ da CDC), devendo ser encaminhado à autoridade policial competente, com comunicação imediata do Juízo da Infância e Juventude. 
Também, há necessidade de cientificação dos pais ou responsáveis do adolescente a quem se atribui a prática do ato infracional sobre a peça da representação, afinal, a participação ativa dos genitores ou responsáveis no procedimento de apuração do ato infracional, inclusive na fase extraprocessual, é relevante para o desfecho do caso e para a correta aplicação de medida de intervenção, se houver necessidade.

\section{b. Direito de ser imediatamente colocado em liberdade, tão logo formalizada sua apreensão}

Segundo dispõe o Estatuto da Criança e do Adolescente (art. 106), “nenhum adolescente será privado de sua liberdade senão em flagrante de ato infracional ou por ordem escrita e fundamentada da autoridade judiciária competente”.

Essa regra, indiscutivelmente, atende às diretrizes do Direito da Criança e do Adolescente, que fixam os princípios da brevidade, excepcionalidade e respeito à condição peculiar de desenvolvimento como orientadores das ações relativas ao adolescente infrator no âmbito do sistema de justiça juvenil.

Destarte, uma vez apreendido em flagrante delito, a autoridade competente deve analisar sem demora a possibilidade de pôr o adolescente em liberdade (art. 10.2, das Regras de Beijing), afinal, o ideal para ele é a permanência em seu lar, o contato com sua família, de modo que a internação provisória apenas legitima-se como último recurso, devendo, na mais remota hipótese, ser aplicada pelo menor prazo possível (art. 13, das Regras de Beijing), quando outras medidas menos onerosas à liberdade não forem adequadas ao caso concreto.

Ainda, vale ressaltar que, à luz da dignidade da pessoa humana, a internação provisória do adolescente, que se submete ao prazo de quarenta e cinco dias (art. 108, do ECA), apenas tem cabimento nas hipóteses que, sendo responsabilizado pela prática do ato infracional, seja possível a imposição de medida socioeducativa de internação, afinal, não há sentido, quando se tutela os direitos do adolescente enquanto pessoa em condição especial de desenvolvimento, restringir sua liberdade (e, com isso, outros direitos que lhe são próprios) sabendo-se que, ao final do procedimento de apuração do ato infracional, caso responsabilizado, possa lhe ser imposta medida menos gravosa que a internação.

Nesse passo, leciona João Batista Costa Saraiva (20 09, p. 61): 
Em verdade há que se levar em conta as disposições do art. 122 do Estatuto, na medida que um fato somente poderá ensejar internação provisória se for apto a ensejar internação definitiva. Não será possível suprimir a liberdade do adolescente enquanto suspeito se de antemão constata-se que, se afirmada sua responsabilidade ao final da apuração o processo, não se configurará hipótese legal de internamento, tendo em vista os 1 imites impostos pelo art. 122. Se vedada a possibilidade de privação de liberdade após apurada a responsabilidade, com maior razão vedada estará enquanto mero suspeito de certa conduta que, se afirmada, não poderá resultarem privação de liberdade.

Assim sendo, tendo em vista a condição especial de pessoa em desenvolvimento, a liberdade do adolescente, enquanto direito fundamental, deve ser entendida como regra no procedimento de apuração do ato infracional, sobretudo porque possibilita o gozo de outros direitos infanto-juvenis, tal como a convivência familiar, podendo ser restringida em último caso, conforme as necessidades pedagógicas desse se r em processo de formação.

\section{c. Direito à igualdade na relação processual, confrontação com testemunhas e} vítimas e produção de todas às provas necessárias à sua defesa, em razão dos princípios do contraditório e da ampla defesa

A igualdade na relação processual, enquanto direito que integra o princípio do devido processo legal, na seara do Direito da Criança e do Adolescente, decorre do protagonismo juvenil que objetiva a norma estatutária, dando possibilidade ao adolescente acusado da prática de ato infracional de, enquanto sujeito de direitos, exercer os mesmos mecanismos que a parte contrária possui para influenciar o convencimento do Juízo da Infância e Juventude, podendo, com isso, requerer a efetivação dos meios de prova que entender pertinentes à sua defesa (ROSSATO, 2016, p. 348).

Essa garantia processual da igualdade decorre do princípio do contraditório e da ampla defesa, que tutela a possibilidade de reação e defesa pessoal e técnica no procedimento de apuração do ato infracional ou de execução de medida socioeducativa, possibilitando ao adolescente o direito de se pronunciar sobre tudo quanto for produzido em juízo pela parte contrária, afinal, mormente em razão da situação de pessoa em condição peculiar de desenvolvimento, o adolescente, no bojo do processo infracional, não pode sofrer qualquer restrição que não seja extensiva ao Ministério Público.

Ainda, esse princípio é contemplado na parte final do item 7.1 das Regras de Beijing, que assegura o direito de confrontação com testemunhas e vítimas, bem como a ampla dilação probatória no referido procedimento. 


\section{d. Direito à defesa técnica, pessoal e ao acompanhamento dos pais ou} responsáveis no procedimento de apuração do ato infracional

O direito à defesa técnica que, de igual modo, está contemplado pelo princípio do devido processo legal, ao qual faz jus o adolescente acusado da prática de ato infracional, decorre da regra constitucional que assegura a imprescindibilidade do advogado à administração da justiça (art. 133, da CF).

Portanto, uma vez sujeitado ao procedimento de apuração do ato infracional e à execução de medida socioeducativa, o adolescente te m o direito à defesa técnica exercida por advogado, consoante se depreende do artigo 227, § $3^{\circ}$, da Constituição Federal, bem como do artigo 207, do Estatuto da Criança e do Adolescente.

E essa defesa técnica deve prezar pelo respeito a todos os princípios orientadores do sistema de justiça juvenil e direitos fundamentais do adolescente, de modo que compete ao defensor atuar ativamente no processo, jamais se conformando com qualquer determinação judicial que esteja em descompasso com as normativas de proteção da criança e do adolescente, bem como com as necessidades pedagógicas desse ser em formação, inclusive no processo de execução das medidas socioeducativas.

Conforme João Batista da Costa Saraiva (2009, p. 55 ):

O atuar desse defensor deve ser enérgico e técnico,não se conformando com um agir "figurativo". O defensor tem de estar comprometido com o supremo valor que defende, a liberdade. Deve se contrapor aos argumentos do Ministério Público na pretensão socioeducativa deduzida na Representação, assim como na vigilância da composição do acordo qu e resulta no concerto da remissão na fase pré-processual.

Ainda que foragido ou ausente o adolescente, a defesa técnica é indispensável, sob pena de nulidade do procedimento de apuração do ato infracional.

O adolescente infrator também possui o direito à defesa material, ou seja, o direito a ser ouvido pessoalmente pela autoridade competente, sendo certo que, conforme a Resolução n. ${ }^{\circ}$ 33/2010 do Conselho Nacional de Justiça, sua oitiva deve ser produzida de modo a evitar prejuízos ao seu desenvolvimento, assegurando-se, ainda, o direito fundamental ao silêncio (artigo 5 , LXIII, da CF), corolário do princípio ad presunção de inocência (artigo 5º LVII, da CF), que também deve ser observado no procedimento de apuração do ato infracional e de execução de medida socioeducativa. 
Esse direito deve ser assegurado ao adolescente não apenas nos atos realizados pelo Juízo da Infância e da Juventude, mas também pelo Ministério Público e pela Defensoria Pública, por meio de seus órgãos, enquanto instituições que também estão encarregadas de tutelar os direitos fundamentais infanto-juvenis.

Outrossim, no procedimento de apuração do ato infracional e de execução de medida socioeducativa, tem direito o adolescente infrator ao acompanhamento dos seus pais ou responsáveis nos atos processuais, ou de solicitar a presença deles, afinal, a participação efetiva dos genitores do adolescente é fundamental para prestar suporte emocional a ele, informar sua conduta pessoal, familiar e social, bem como prestar esclarecimentos diversos que poderão servir de suporte para a autoridade judicial competente no momento de aplicação de execução de eventual medida socioeducativa, sendo também relevante a participação dos pais ou responsáveis na fase de execução dessa medida.

\section{da lei}

\section{e. Direito à assistência judiciária gratuita e integral aos necessitados, na forma}

Decorrente do princípio constitucional que assegura o acesso à justiça, no caso, ao sistema de justiça juvenil, o direito à assistência judiciária gratuita e integral aos necessitados, na forma da lei (art. 5º, inc. LXXIV, da CF), assegura ao adolescente que não tenha condições de fazer-se representar por profissional habilitado, que exercerá a defesa técnica, o direito a ser assistido por um defensor público que, conforme asseverado anteriormente, deverá participar ativamente do processo, manifestando-se no sentido de contraposição à pretensão apresentada pelo Ministério Público (ROSSATO, 2016, p. 348).

Cumpre lembrar, ainda, que, nas comarcas onde não h aja defensor público, o Juízo da Infância e da Juventude deverá nomear em favor do adolescente infrator que não esteja representado por advogado um defensor para o exercício da defesa técnica (art. 141, § $2^{\circ}$, do ECA), evitando-se, com isso, que o adolescente seja processado sem a assistência de um advogado, situação que implica nulidade do procedimento infracional, por latente violação aos direitos e garantias processuais em que se pauta o sistema de justiça juvenil.

3.1 Considerações sobre as garantias processuais previstas no artigo 111, do Estatuto da Criança e do Adolescente 
$\mathrm{Na}$ perspectiva do direito infanto-juvenil, as garantias processuais asseguradas ao adolescente infrator, acima expostas, integram o sistema especial de justiça que lhe é assegurado enquanto pessoa em condição peculiar de desenvolvimento.

Aliás, consoante leciona João Batista Costa Saraiva(2016, p. 89):

O Estatuto da Criança e do Adolescente se assenta n o princípio de que todas as crianças e adolescentes, sem distinção, desfruta $m$ dos mesmos direitos e sujeitam-se a obrigações compatíveis com a peculiar condição de desenvolvimento que desfrutam, rompendo, definitivamente, com a ideia até então vigente de que os Juizados de Menores seriam uma justiça para os pobres, na medida em que na doutrina da situação ir regular se constatava que para os bens nascidos, a legislação baseada naquele primado lhes era absolutamente indiferente.

Desse modo, é possível depreender que o devido processo legal, na seara do direito da criança e do adolescente, demanda dos operadores do direito uma vigilância cautelosa no que toca aos processos de apuração dos atos infracionais, inclusive na fase extraprocessual, bem como de execução de medida socioeducativa, justamente em razão da condição de seres em formação dos adolescentes infratores, os quais comumente são postos à presença da autoridade judicial não a partir de suas falas, mas pelas de um adulto, que nem sempre reproduz os seus reais anseios e necessidades pedagógicas.

Enquanto essa cautela não existir em relação às garantias processuais dos adolescentes infratores, os direitos fundamentais desses seres em processo de formação serão violados a sua reeducação por meio de mecanismos que assegurem a promoção de sua dignidade jamais será conquistada.

\section{Conclusão}

Os reflexos do princípio constitucional do devido processo legal repercutem no direito fundamental à liberdade, que está condicionado ao macro princípio da dignidade da pessoa humana, fundamento do Estado de Direito e de todos os instrumentos normativos que tutelam os direitos infanto-juvenis.

No que tange aos adolescentes em conflito com a lei, a liberdade, enquanto direito natural, tem um tratamento peculiar, que reflete significativamente no princípio constitucional do devido processo legal, na medida em que as garantias processuais dele decorrentes são norteadas por princípios específicos, próprios do Direito da Criança e do Adolescente. 


\section{REFLEXOS DO PRINCÍPIO CONSTITUCIONAL DO DEVIDO PROCESSO LEGAL NO DIREITO INFANTO-JUVENIL}

Referidas garantias processuais, que integram o sistema de justiça juvenil, pautado nos princípios da excepcionalidade, brevidade e melhor interesse da pessoa em desenvolvimento, têm por propósito assegurar ao adolescente infrator a existência de um processo no qual suas necessidades pedagógicas seja m corretamente identificadas para que, na mais remota hipótese, se houver necessidade de imposição de medida socioeducativa, essa intervenção atenda os objetivos da sua reeducação e reinserção social, contribuindo, destarte, para sua formação enquanto ser humano.

Subtrair do adolescente essas garantias processuais ou aplica-las em descompasso com os princípios basilares do direito infanto-juvenil, deixando de observar o melhor interesse e a prioridade absoluta que esses personagens reclamam, implica retrocesso tanto no aspecto jurídico quanto no social.

Apesar do avanço legislativo com a promulgação da norma estatutária no país em termos de criança e adolescente, bem como da ratificação de instrumentos internacionais que referenciam os direitos infanto-juvenis, somente a produção legislativa não é suficiente para a concretização do sistema de justiça juvenil, no qual a pretensão da eficácia das garantias processuais do adolescente infrator está inserida. É indispensável, pois, estabelecer mecanismos e ações que visem a plena efetivação dos direitos fundamentais desses sujeitos em peculiar condição de desenvolvimento.

As garantias processuais consubstanciadas no artigo 111 do Estatuto da Criança e do Adolescente e em instrumentos internacionais de proteção à infância e à juventude, decorrentes do princípio constitucional do devido processo legal, por si sós, são insuficientes para assegurar ao adolescente infrator um sistema de justiça que realmente atenda suas necessidades pedagógicas.

Desse modo, é necessário haver um engajamento sólido de todos os responsáveis pela promoção dos direitos fundamentais desses personagens para que, por meio da criação e execução de políticas públicas adequadas, a responsabilização no âmbito da justiça penal juvenil atenda realmente as necessidades pedagógica $\mathrm{s}$ desses sujeitos em processo de desenvolvimento, respeitando-se seus direitos fundamentais, em especial a liberdade, por meio do cuidado constante que reclamam. 


\section{Referências Bibliográficas}

ALKIMIN, Maria Aparecida. Violência sexual contra a criança e o adolescente: abordagem da violência sexual intrafamiliar de acordo com o sistema de proteção jurídico-penal brasileiro e português. Curitiba,. CRV, 2016.

BOBBIO, Norberto. A Era dos Direitos. Nova Ed. Tradução de Carlos Nelson Coutinho. Apresentação Celso Lafer. Rio de Janeiro, Elsevier, 2004.

CHIMENTI, Ricardo Cunha; CAPEZ, Fernando; ROSA, Márcio F. Elias; SANTOS, Marisa F. Curso de Direito Constitucional. São Paulo: Saraiva, 2006.

FERREIRA, Pinto. Comentários à Constituição brasileira. São Paulo: Saraiva, 1989.

ISHIDA, Válter Kemji. Estatuto da criança e do adolescente: doutrina e jurisprudência. $13^{\mathrm{a}}$ ed. - São Paulo: Atlas, 2011.

MORAES, Alexandre de. Direito Constitucional. São Paulo: Saraiva, 2007.

NUCCI, Guilherme de Souza. Estatuto da Criança e do Adolescente Comentado: em busca da Constituição Federal das Crianças e dos Adolescentes. $3^{\text {a }}$ ed. rev., atual. e ampl. Rio de Janeiro: Forense, 2017.

PAULA, Paulo Afonso Garrido de. Direito da Criança e do Adolescente e tutela jurisdicional diferenciada. São Paulo: Revista dos Tribunais, 2002.

PEREIRA, Tânia da Silva. Direito da Criança e do Adolescente - Uma proposta interdisciplinar. Rio de Janeiro: Renovar, 2008.

PEREIRA, Tânia da Silva (Coord.) O melhor interesse da criança: um debate interdisciplinar. Rio de Janeiro: Renovar, 2008.

PIOVESAN, Flávia. Temas de Direitos Humanos. 4ª ed. São Paulo: Saraiva, 2010.

ROSSATO, Luciano Alves. Estatuto da criança e do adolescente: Lei n. 8.069/90 comentado artigo por artigo. São Paulo: Saraiva, 2016.

SARAIVA, João Batista Costa. Adolescente em conflito com a lei: da indiferença à proteção integral. Uma abordagem sobre a responsabilidade penal juvenil. Porto Alegre: Livraria do Advogado Editora, 2009. 
Adolescente e responsabilidade penal: da indiferença à proteção

integral. 5a ed. rev. e atual. Porto Alegre: Livraria do Advogado Editora, 2016.

SCHECAIRA, Sérgio Salomão. Sistema de Garantias e o direito penal juvenil. $2^{\mathrm{a}}$ ed. rev. e atual. São Paulo: Editora Revista dos Tribunais, 2015.

SILVA, José Afonso da. Curso de Direito Constitucional Positivo. São Paulo: Malheiros, 2003.

VERCELONE, Paolo. Estatuto da Criança e do Adolescente Comentado. Cury, Amaral.

SILVA e MENDÉZ. São Paulo: Malheiros, 2005. 